This item was submitted to Loughborough's Research Repository by the author.

Items in Figshare are protected by copyright, with all rights reserved, unless otherwise indicated.

\title{
CASPA: Coursework and Assessment Scheduler for Programme
}

\section{Administration}

\section{PLEASE CITE THE PUBLISHED VERSION}

http://dx.doi.org/10.21125/inted.2016.0211

\section{PUBLISHER}

IATED

VERSION

VoR (Version of Record)

\section{PUBLISHER STATEMENT}

This work is made available according to the conditions of the Creative Commons Attribution-NonCommercialNoDerivatives 4.0 International (CC BY-NC-ND 4.0) licence. Full details of this licence are available at: https://creativecommons.org/licenses/by-nc-nd/4.0/

\section{LICENCE}

CC BY-NC-ND 4.0

\section{REPOSITORY RECORD}

Lowery, Caroline A., and Sarah E. Bamforth. 2019. "CASPA: Coursework and Assessment Scheduler for Programme Administration”. figshare. https://hdl.handle.net/2134/24900. 


\title{
CASPA: COURSEWORK AND ASSESSMENT SCHEDULER FOR PROGRAMME ADMINISTRATION
}

\author{
Dr C. Lowery, Dr S. Bamforth \\ Loughborough University (UK)
}

\begin{abstract}
Technology in education can be used in a variety of different ways. The most obvious is its direct application to help facilitate learning. However, technology can also be used in more subtle ways to benefit student learning and to ease the burden on academics and staff so that they in turn are able to spend more time interacting with students. The Engineering Schools at Loughborough University approached the Centre For Engineering and Design Education (CEDE), looking to the Centre, with its blend of pedagogy and technology skills to unpick and resolve the issues that the Schools were facing with regard to assessing students. With myriad modules on multiple programmes, live oversight of the assessment demands on students was difficult to achieve with the Schools' existing practices; the potential for over burdening students due to assessment bunching was a real issue. There were also practical issues of managing coursework hand in and return for large numbers of students.

Working in close collaboration with the Engineering Schools CEDE has developed, piloted and rolled out CASPA, a Coursework and Assessment Scheduler for Programme Administration. This paper describes CASPA and shares the key findings of a study, undertaken by CEDE into CASPA' $s$ reception and impact on students and administrators and how they would like to see CASPA enhanced. Research was undertaken with administrative staff in the form of focused discussions and an online questionnaire survey. Student views have been provided using a paper based questionnaire survey of 88 students. The key findings of the research are presented in this paper, including the findings that students value the reassurance that CASPA gives by keeping a record of assessment submissions and work returned whilst providing a centralised place for their assessment deadlines to help them keep track of their schedules and organise their work. The introduction of CASPA has had a huge impact on the demands of administrators time, greatly reducing the time needed to receive and return coursework. With this freed up time it has been possible for Schools to make greater use of their administrators for the benefit of the students. One school in particular has introduced feedback quality monitoring into the coursework return process. Having trained the administrators in the level and quality of feedback to students, administrators are now able to monitor and flag any issues in feedback quality.
\end{abstract}

Keywords: Innovation, technology, research projects, enhancing undergraduate experience.

\section{CASPA}

\subsection{The foundations of CASPA}

There is always too much demand on too little staff time, whether administrative, academic or technical staff. This is particularly the case for administrative tasks relating to assessments. The myriad of teaching and assessment methods used in Higher Education (HE) to cater for diverse student learning styles [1] has meant the development of a diverse range of assessment types (for example written reports, workshops practicals, performances, presentations, examinations) necessitating a correspondingly wide variety of ways for students to submit their work or register their participation in an assessment.

CASPA (Coursework Assessment Scheduler for Programme Administration) is an online system that has stemmed from the requirements of administrators within the Faculty of Engineering to provide an efficient way for staff to record the submission of physical coursework by students. In its infancy, CASPA was developed solely as a coursework submission tool to help with high demands on staff time for the submission of students' physical (hard copy) work (such as written reports etc.). The Civil and Building Engineering (CBE) Department uses a weekly one-hour time slot to collect all physical coursework items for their School. This meant, prior to CASPA, that extra staff had to be used to allow hundreds of students to submit their physical work within this single one-hour slot. The existing paper based system was both logistically challenging and inefficient. In 2010, the 'Coursework Submission 
Tool' software was developed and meant that submissions could be recorded electronically by students swiping their ID cards whilst staff selected the correct items to submit from a drop down assessment list. This greatly reduced the demands on staff time, reducing the need for five members of staff to just two members and providing a very practical solution to view and record student submissions quickly and efficiently in a single place.

\subsection{The growth of CASPA}

The benefits in using the automated Coursework Submission Tool were soon recognised and there became a growing demand for the system to be used by other departments within the University. In addition, there was growing demand for the tool to be further developed to extend to other assessment types in order to both record all forms of student submissions and assessment participation and additionally to register the return of work back to students. This need for a standardised approach came to the fore in 2011/12 when Loughborough University underwent a restructure and departments were merged to become 10 University Schools. Historically, departments had used their own procedures and forms to issue assessments, record student submissions and return student work and feedback. Thus, amongst the emerging engineering and design schools there was now a disparate set of approaches used to provide assessment timetables to students, to record student submissions, to record the return of work back to students and to provide timely feedback. Whilst within the newly created schools, there had been some adoption of practices between merging departments, between the new schools the approaches for the administration of coursework remained very different with no drive to align these approaches.

At that time it was recognised that the existing Coursework Submission Tool could be enhanced to not only deal with the submission of different types of assessments but also to provide assessment maps and schedules for students and staff and to additionally formally record the return of work or feedback to students. Consequently, in 2012 the CASPA System was developed and has undergone a number of enhancements to: accommodate the changing needs of staff and students regarding assessment submissions; record the return of work back to students; and schedule assessments within university degree programmes.

The enhancements made to CASPA meant that it was widely adopted by Schools within the University. By the 2013-2014 academic year there were four University Schools using CASPA for their coursework submissions and returns covering 985 assessments with 24,858 student submissions through CASPA. In the 2014-2015 academic year these figures increased significantly with six University Schools using CASPA covering 2006 assessments with 43,708 student submissions. CASPA's increasing popularity as a system has meant that this academic year mechanisms are being put into place to enable CASPA to be used throughout Loughborough University in its entirety by all 10 Schools.

\subsection{An overview of the CASPA system and its enhancements}

CASPA has been greatly enhanced over the last four years to meet the changing needs of staff and students. It now serves as an online system to enable staff and students in dealing with mapping degree programme assessments, assessment scheduling, recording student submission and/or participation for any type of assessment and to record formally the timing for return of work back to students.

CASPA's enhancements over the last four years have been undertaken by loosely following an agile software development approach [2]. CASPA's developers have worked closely with users of the system to determine key functionality requirements and to assess the usability of CASPA and its interface. The system has been developed in response to the changing needs of staff and students. User stories have been used to help direct the needs of users and to identify key functionality required within the system. The decisions to add an enhancement to CASPA or to change its functionality have been agreed by CASPA Key Users based on the needs of users as a whole rather than the bespoke requirements of individual users. This has allowed the system to grow incrementally and serve the needs of the entire University.

The agreed priorities and enhancements made to CASPA over the last two years have meant that the system comprises some core functionality relating to assessments scheduling, recording of student submission/participation for an assessment and recording of the return of work/feedback to students. Within these core areas, CASPA has been developed to enable specific tasks to be undertaken efficiently within a single system in line with the requirements of key users. 
As a result of the findings presented in this paper, CASPA has undergone further enhancements during 2015. The user interface has been enriched and includes additional features for filtering information (see Fig. 1). Two key enhancements have been added to facilitate assessments with staggered deadlines and to gather assessment information from Learn/Turnitin regarding virtual assessments.

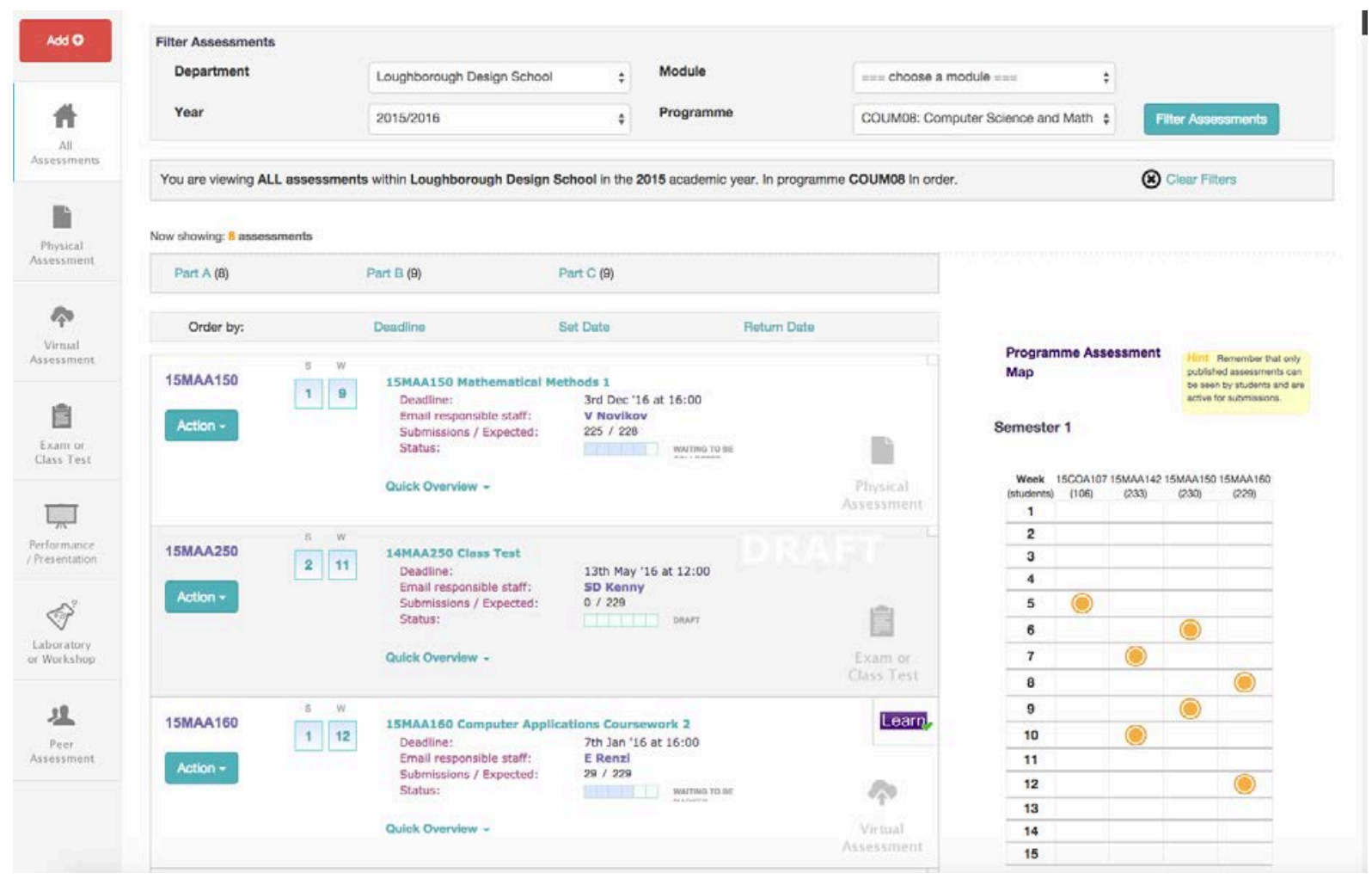

Fig. 1 CASPA Department Overview with filtering options

CASPA now interfaces with a number of different software systems including: Loughborough University's Student Information System (LUSI), the University's Virtual Learning Environment (Learn), Turnitin (an internet-based plagiarism-prevention service) and Co-Tutor (Loughborough University's student and staff relationship management system). This means that CASPA is able to gather both electronic information regarding assessments and submissions and also to provide its own data to other software systems used within the University.

Assessments with multiple deadlines can now be added to CASPA. This staggered assessment type means that users are able to have a different deadline for each time the same assessment is undertaken by a different set of students. An example of this might be when the same laboratory assessment is run multiple times across a semester allowing different sets of students to attend the laboratory session on different dates. The staggered assessment feature means that the laboratory assessment can now have different submission deadlines depending on the laboratory session attended.

The findings from the yearly National Student Survey ${ }^{1}$ (NSS) showed lower satisfaction scores for assessment and feedback compared with other aspects of undergraduate study [3]. Key issues raised by the students included concerns with assessment bunching, overburdening and timely feedback. Accordingly, CASPA has been developed to provide a consistent mechanism to enable mapping of programme assessment schedules in order to support the minimizing of assessment bunching for students and to support timely feedback.

In addition, CASPA can be used as a mechanism to aid the monitoring of student engagement through its ability to view a record of student submissions and participation in assessments for their programme. The system can also indicate whether a student has submitted work on time or late. The

\footnotetext{
${ }^{1}$ An annual survey completed by final year University undergraduates in the UK
} 
information provided by CASPA can be used to indicate if a student is failing to submit their work or participate in assessments suggesting that a student may be disengaging from their study. The addition of a 'student view' feature for staff allows them to see the assessment schedule for a particular student enabling Personal Tutors to provide informed support for pastoral care.

CASPA can be used as a live assessment scheduler for staff to view clearly every type of assessment scheduled for a particular programme, programme year and/or module (see Fig. 2). Each assessment can additionally be viewed in isolation to provide further detail for an assessment. The ability to examine the entire programme schedule means that staff are able to see instantly where student overburdening in assessments might occur providing the opportunity for the timetabling of assessments to be modified. The enhanced functionality within CASPA enables staff to sort and filter the data presented to them so that only the key information required is displayed. Students can view their current assessment schedule to aid with their own time management and can also instantly view any submissions/participation they have made and see records of work returned back to them.

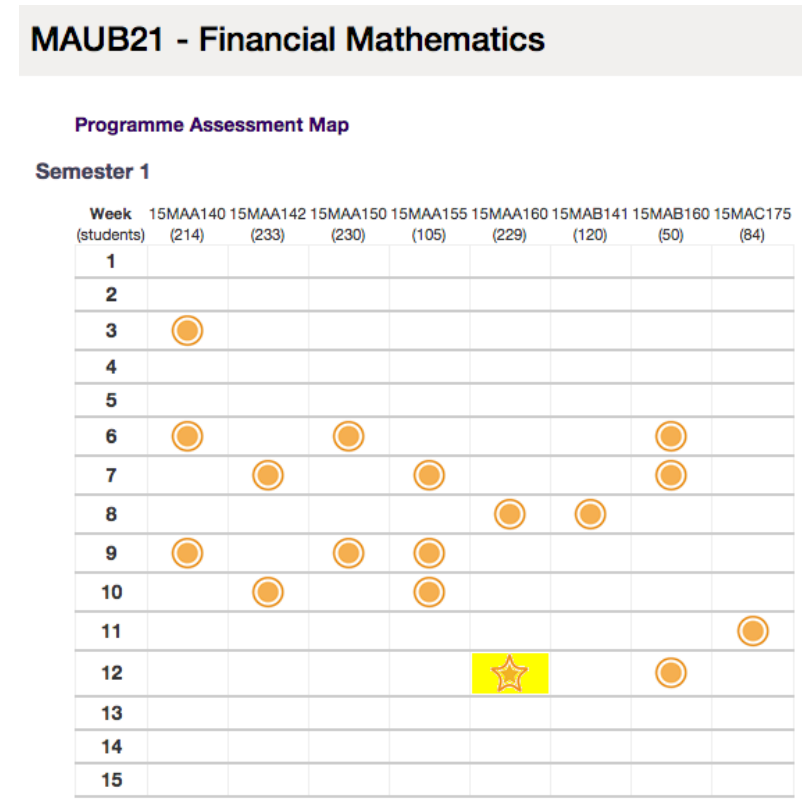

\section{Fig.2 CASPA Programme Assessment Map}

A student's work submission or participation can be registered by each student via an automated QR (Quick Response) kiosk and coversheet, by manual staff entry and/or by student virtual submission through Learn or Turnitin. Registering of submissions or participation in an assessment can be recorded by an individual student or by groups of students. The system leaves the selection of group members for submission to the students to remove the responsibility from staff (this can be achieved quickly by students through a drop down list). Similarly, the recording of the return of work to students can be achieved in CASPA by students using the QR kiosk, by staff manual entry or by virtual return through Learn or Turnitin. This allows staff and students to view all types of assessments, submissions/participation and a record of feedback in a single consistent place.

When a submission or participation is recorded in CASPA students can be sent an email receipt, minimising physical paperwork and keeping a consistent central record. Communication between staff and students is facilitated by the ability of staff to email different groups or cohorts of students and programme of study staff as necessary.

The large numbers of students and staff using the system has necessitated the production of user guides covering the initial setting up of the system and its use from an occasional user, key user and student perspective. In addition, further smaller user guides have been developed for the two key enhancements (staggered deadlines and gathering virtual assessment data) made this academic year. The production of these guides and using key CASPA users (see Section 2.2.1) within each 
School for initial queries has greatly reduced the time needed to show staff and students how to use the system effectively.

\section{A STUDY OF CASPA'S RECEPTION AND IMPACT ON STUDENTS AND ADMINISTRATORS}

At the start of 2015, following the development of CASPA and its adoption by the Engineering and Design Schools, work was undertaken to:

1. understand the reception of CASPA and its impact and

2. to identify further ways in which it could be enhanced.

It was important to research this both from the perspective of the students and the administrative staff in order to understand the views of both sets of end users. The research comprised focused discussions and an online questionnaire survey with key administrative users and additionally, a paper based questionnaire survey of 88 students.

\subsection{Method}

A number of research methods were used with staff and students. A focus group discussion with 12 administrative staff was used in order to produce rich data (Cohen et al., 2000). The findings from the focus group were then used to inform an online survey, which allowed the study to access staff unable to attend the focus group.

A paper-based questionnaire was used to gather the student perspective from students from two different Schools, Civil and Building Engineering (CBE) and the Aeronautical Automotive, Chemical and Materials Engineering School (AACME). Civil and Building Engineering Students were approached by CEDE staff after handing in their coursework and asked to participate in the survey. In total, 88 students participated in the CASPA evaluation survey. Only a very few students declined to participate, leading to a high response rate. Not all 88 students answered all of the 9 questions on the questionnaire. The number of students who responded to a particular question is shown in brackets (n) in the analysis. The percentages given are calculated on the number of students who responded to that particular question.

Administrative staff distributed the questionnaire in the AACME School. It is not known how many were distributed, however, 14 responses were received. As the relative response rate is not known, and given the limited number of responses, the data from the AACME School is only used to highlight any general similarities or differences with the response from the School of Civil and Building Engineering.

\subsection{Findings}

\subsubsection{Staff perspective}

The findings from the focus group and survey highlight the very different ways in which the coursework scheduling, hand-ins and returns are administered across different schools. For example, just in terms of hand in procedures, some schools require students to hand in assignments to staff within a one hour window. Other schools want their students to be able to submit to a drop box any time within a 24 hour timeframe. The functionality within CASPA has had to accommodate these differences.

The findings of the questionnaire highlight some of the issues that Schools faced. The table below shows issues with School coursework management processes before the introduction of CASPA, how CASPA has helped to improve the process and the benefits that staff have encountered since the introduction of CASPA. One key consequence of the introduction of CASPA, identified through the focus group discussions, is how it has freed up staff time enabling them to engage in quality assurance activities. Administrative staff in one particular school are now able to monitor the quality of the feedback that that is being returned to students; checking to ensure that feedback is of a specified standard and escalating any identified issues to senior managers. As part of this quality monitoring, CASPA also enables this school to identify quickly if feedback is being returned to students later than its 3 week deadline. Administrative staff report that since the introduction of this quality monitoring process, the number of cases that have to be reported have dwindled. The findings of the survey and those of the focus group suggest that the majority of staff have seen an improvement in their School's 
coursework management process and that all report numerous benefits from using CASPA, depending on how CASPA has been applied within their School.

Table 1: Impact of CASPA

\begin{tabular}{|c|c|c|c|}
\hline School & $\begin{array}{l}\text { Issues with School's } \\
\text { coursework Management } \\
\text { Process - Pre CASPA }\end{array}$ & $\begin{array}{l}\text { Post CASPA - How CASPA } \\
\text { has helped to improve School } \\
\text { coursework management } \\
\text { process. }\end{array}$ & $\begin{array}{l}\text { Benefits of using } \\
\text { CASPA }\end{array}$ \\
\hline 1 & $\begin{array}{l}\text { "Slow - had to wait for each } \\
\text { student to get ID card out } \\
\text { and complete a hard copy } \\
\text { slip properly. Hard work to } \\
\text { get through large number of } \\
\text { students before } 10.00 \text { am } \\
\text { deadline." }\end{array}$ & $\begin{array}{l}\text { "Very quickly get through large } \\
\text { number of students, who really } \\
\text { appreciate the coursework cover } \\
\text { sheet. Records are kept and can } \\
\text { be used for other admin } \\
\text { processes. } 10.00 \text { am deadline } \\
\text { automatic so fair to all. [QR] } \\
\text { Coversheets can be printed off } \\
\text { quickly on hand-in morning if } \\
\text { students forget to do them. Fast } \\
\text { process for hand-in and hand- } \\
\text { back. Now doing PG students } \\
\text { on the system as well." }\end{array}$ & $\begin{array}{l}\text { "Fast to "zap" in and } \\
\text { out the coursework, } \\
\text { not waiting for } \\
\text { students to get ID } \\
\text { card out. Accurate } \\
\text { record keeping. } \\
\text { Students really like } \\
\text { the function of setting } \\
\text { up their groups and } \\
\text { producing a group } \\
\text { cover sheet." }\end{array}$ \\
\hline 2 & "No issues" & $\begin{array}{l}\text { "No improvement as I take the } \\
\text { information from the workload } \\
\text { model." }\end{array}$ & $\begin{array}{l}\text { "Less disruption to } \\
\text { the office. Saves on } \\
\text { time having to use } \\
\text { Co-Tutor to send out } \\
\text { submit emails Can } \\
\text { pass work to ML } \\
\text { [Module Leader] in a } \\
\text { more timely manner." }\end{array}$ \\
\hline 3 & $\begin{array}{l}\text { "Long queues at reception to } \\
\text { submit coursework, students } \\
\text { claimed to have handed in } \\
\text { when they hadn't." }\end{array}$ & $\begin{array}{l}\text { "Returns has definitely been a } \\
\text { big improvement, we no longer } \\
\text { have to obtain signatures, } \\
\text { scanning is much faster } \\
\text { therefore have less queues." }\end{array}$ & $\begin{array}{l}\text { "See previous [to the } \\
\text { left]." }\end{array}$ \\
\hline 4 & $\begin{array}{l}\text { "I used to have morning and } \\
\text { afternoon slots for both } \\
\text { coursework hand-in and } \\
\text { hand-back. Now with the } \\
\text { CASPA System I have just a } \\
\text { one hour hand-in slot and } \\
\text { two, two hour hand-back } \\
\text { slots." }\end{array}$ & $\begin{array}{l}\text { "It is now a cleaner and slicker } \\
\text { process and I am not now tied to } \\
\text { my desk waiting for students to } \\
\text { turn up to either hand-in or } \\
\text { collect their coursework." }\end{array}$ & $\begin{array}{l}\text { "I now have extra } \\
\text { time to get on with } \\
\text { more important } \\
\text { aspects of my job." }\end{array}$ \\
\hline
\end{tabular}

The focus group and questionnaire identified a number of areas where administrative staff could envisage additional improvements to their School's coursework management process if further features were added to CASPA. Features identified included:

- "Automated roll forward of dates";

- "Hand in desk to show deadline time as ours are not standard and it would be easier to look in one place for information";

- "Ability to print reports; A system in which both Full-Time and Part-Time Coursework can be logged through one screen";

- "Ability to accommodate staggered assessments"; and 
- "The ability for CASPA to link with the University's VLE in order to accommodate virtual submissions".

Coming out of the focus group with the administrative staff was the desire from staff to act in the future as a key user group, both to inform the direction of future CASPA developments and to act as advisors to Schools newly taking up CASPA. Utilising this user group, their priorities for enhancements to CASPA for the academic year were identified; staff prioritised the ability to accommodate staggered assessments; and the ability for CASPA to link with the University's VLE in order to accommodate virtual submissions.

\subsubsection{Student perspective}

When asked about the benefits of using the CASPA system to submit work, the most prevalent response from the CBE participants ( $n=81$ ) was that the system was a 'quick (46\%) and easy (36\%)' way to submit their work. They like the reassurance of having a record of when their work has been submitted and reported that having a centralised place for their coursework deadlines helped them keep track of their deadlines and organise their work. Other free text responses given to describe the benefits of CASPA related to seeing the deadline in one place $(11 \%)$, having confirmation that the University had received the coursework (10\%), and that the system was simple to use $(10 \%)$. The response from AACME students suggests that they too find the system quick and easy and value having their deadlines viewable in once place.

When asked how useful it was to view their own assessment schedule $(n=71)$ the most prevalent free text response from CBE students was that they found it found it very useful (34\%). Only $2 \%$ found the system only moderately helpful and only $1 \%$ responded by saying it was not really helpful. The second part of the question asked how the system helped them to plan their assessment work and submissions $(n=48)$. Of the responding students, $27 \%$ and $17 \%$ respectively cited the planning and time management benefits gained through using CASPA. There were $14 \%$ who mentioned one or more aspects afforded by the ability to view assessment deadlines (including exact dates, updated deadlines and keep track). Again, all of the AACME students who answered this question responded positively.

The prevailing CBE response $(n=65)$ when asked how CASPA helps them to save time in submitting work and receiving work back was that it does not (22\%). (Of this $22 \%$, almost half clarified that the issue was with the time it took to return coursework; from their perspective CASPA saved time submitting but not in the return of work.) Responding students (65) noted that time was saved submitting coursework due to already completed coversheet (12\%), the quick QR code scanning process $(11 \%)$, the process being easy $(9 \%)$, and a quick process $(5 \%)$. Students felt that it did not save time in the return of coursework citing that they still had to collect the work by hand $(2 \%)$ which was a slow and crowded process (2\%). AACME students were also mixed in their response to this question. Reduced waiting in line time was given by some students as to why CASPA saves them time. One student cited receiving an email communication informing them that their marked worked was now available, as enabling them to retrieve their work quickly. Other AACME Students were unhappy that they still had to be physically present to hand in their work.

When asked about the usefulness of being able to create student groups and using the QR coversheets for submitting work $93 \%$ of the 69 CBE students who answered this question responded positively about these features. $67 \%$ described it as very useful. Only $8 \%$ responded that they had not used at least one of these features. Only one person qualified their response with a criticism of the system. This person said "Like the QR codes. Sometimes a pain to have everyone sign if its last minute." AACME students were overwhelmingly positive about the usefulness of the QR coversheets. Many felt that the feature saved time and one cited that it made it less likely for a team member to be left out.

When questioned, there were a number of features identified by the CBE respondents $(n=62)$ as working particularly well. These included:

- The coversheets (35\% of respondents). In particular, the creation of coversheets (15\%) and ease of printing (8\%) were identified as working particularly well. The ability to select group members easily was also named by $6 \%$ of respondents. 
- The coursework scheduler (32\% of respondents); $18 \%$ of respondents specifically identified the ability to see the deadline dates in the calendar. Students also liked the fact that these were organised week by week (6\%).

- The coursework hand in (19\%). In particular the QR codes (11\%).

- Also identified were the ability to track coursework hand in, email confirmations and the speed of confirmation.

When asked about the things within the CASPA system that irritated them, $40 \%$ of CBE respondents $(n=57)$ answered 'nothing'. Clarity was an issue for $12 \%$ of respondents, with comments made about the layout of the list of coursework "It's annoying how everything is on one long list" (5\%); "the assessment schedule isn't very easy to read/could be more clear or detailed" (4\%); completed submissions not being removed from the schedule (2\%); "how the deadlines are in line with the calendar"; and the fact that the system "brings up all group deadlines not just my specific groups" $(2 \%)$.

\section{CONCLUSIONS}

Originally conceived as an efficient way for staff to record the submission of physical coursework by students, the growth of CASPA into a comprehensive online system for managing assessments has seen its rapid uptake within the University.

Students find CASPA quick and easy to use, they particularly like the ready-made coversheets, the easy addition of group members to the coversheets and the combination of the QR code and scanner for a quick coursework submission. They appreciate having confirmation that the University has received their coursework, them with proof that they have submitted it. Students also value the ability to keep track of their deadlines through the online scheduler and use this to help plan when they work on their assignments.

The perception of the students, in at least the School of Civil and Building Engineering, is that CASPA does not reduce the time it takes for them to receive back marked coursework. No data is provided to indicate whether this is an issue within CASPA or the way it is implemented within the School. Only a few negative comments were made about CASPA, making it difficult to identify if the issues raised are a feature of personal preference or a wider issue. In the future it may be worth exploring the way assessments are listed in one long list within CASPA; investigating whether completed assignments could be removed from the schedule; and seeing if it would be possible for the system to only bring up deadlines for the user's group rather than all groups. Issues relating to group deadlines appearing on student calendars has been resolved for this academic year by CASPA's ability to deal with staggered laboratory groups for the same assessment. This has meant that students will only see the assessments for their particular laboratory group.

In order to be able to support CASPA as it has grown in popularity within the University, an informal mechanism has developed whereby key CASPA users within each School act as the initial point of call for queries from staff and students. This has also served to promote the use of CASPA within each School and into other Schools within the University.

Staff have been instrumental in enhancing CASPA, helping to ensure a user focused system. Maintaining a user centred approach in the future is important. However, the rise in the uptake of CASPA has led to an increase in user numbers from Schools with diverse needs. Consequently, the gathering of user-requested enhancements and additions to the system and their prioritisation has to be managed carefully in order to ensure that the system is as efficient and user friendly as possible across the University. Working closely with key users and utilising user stories will be instrumental in delivering this as will the ability to evaluate the system as it continues to evolve.

\section{REFERENCES}

[1] Lowery, C. A. (2009). Adapting to student learning styles in a first year electrical/electronic engineering degree module. Engineering Education, Journal of the Higher Education Academy Engineering Subject Centre 4(1), pp 52-60.

[2] P. Abrahamsson, O. Salo, J. Ronkainen, and J. Warsta, (2002) Agile software development methods: Review and Analysis. Espoo, Finland: Technical Research Centre of Finland, VTT 
Publications 478, Available online: http://www.vtt.fi/inf/pdf/publications/2002/P478.pdf [Accessed on 4th January 2016]

[3] Higher Education Academy (2013) HEA Feedback Toolkit. HEA, York, UK. Available at: https://www.heacademy.ac.uk/sites/default/files/resources/feedback toolkit whole1.pdf [Accessed on 4th January 2016]

[4] Cohen, L., Manion, L. and Morrison, K. (2000) Research Methods in Education. RoutledgeFalmer, London, UK. 